\title{
Democratic or Autocratic Leadership Style? Participative Management and its Links to rewarding Strategies and Job Satisfaction in SMEs
}

\author{
By Joanna Dyczkowska* \\ Tomasz Dyczkowski
}

\begin{abstract}
The paper aims at detecting relations between participative management and rewarding strategies as well as employees' job satisfaction in SMEs. Unlike many studies which examine effectiveness of rewarding policies from a managerial perspective, the article takes employees' point of view. The empirical part of the paper presents conclusions resulting from analyses of: employee strategic awareness, involvement in goal-setting processes and integration in discussion on company performance, linked to diverse rewarding systems applied in Polish enterprises. Results presented in the paper refer to data from 93 SMEs and 86 large companies, collected at the turn of 2013 and 2014. The authors' research contributes to the discussion on rewarding strategies, demonstrating that involvement of employees in managerial activities is a precondition for developing performance-based rewarding strategies, and that such involvement makes employees more satisfied with their work. Thus the paper fills in the research gap on linking leadership styles with forms of and satisfaction with remuneration systems.
\end{abstract}

Keywords: SMEs, participative management, Poland, rewarding systems

\section{Introduction}

A primary motivation to conduct a study on participative management with a reference to Polish small and medium companies (SMEs) stemmed from the observed, and experienced, economic and social transformation that Poland has undergone over the recent 13 years, after joining the European Union on May 1st 2004. Apart from the unquestionable economic boost that the said event triggered, a radical change in labor market has been observed. Still young just 15-year old (1989-2004) - Polish free market economy, with enterprises operating there, had to face a challenge of a free flow of labor at the Common Market. Obviously, Polish companies could not - and still cannot - offer competitive pays in comparison to other European countries. At the end of 2015 the average remuneration in Poland, according to OECD data (see Average annual wages, 2017) was still 3.5 times lower than in neighboring Germany and 4.1 times lower than in the United Kingdom. That fact contributed to the wave of labor-related migrations. The abovementioned countries were the top destinations of Poles, receiving officially 435 and 612 thousand Polish migrants respectively (see International migrations of citizens, 2013, p.172). Moreover, it turned out

\footnotetext{
* Assistant Professor, Wroclaw University of Economics, Poland.

* Assistant Professor, Wroclaw University of Economics, Poland.
} 
that SMEs, which generate $70.1 \%$ of working places outside financial and public sectors (see Activity of non-financial..., 2014, p.54), found themselves unable to beat international corporations in the war for talents. The foregoing facts make a research on financial and non-financial stimuli to employees' job satisfaction particularly relevant from the Polish perspective.

This paper aims at detecting and defining relations between participative management- being a consequence of prioritizing the democratic leadership style over the autocratic one - and rewarding strategies as well as employees' satisfaction with those solutions. It should be noted that participative management in this study is reflected by: employee strategic awareness, involvement in goalsetting processes and integration in discussion on company performance. A situation in Polish SMEs is referred to that of large businesses. Unlike the vast majority of studies which explore effectiveness of various HRM solutions from a managerial perspective, this examination takes the employees' point of view.

The structure of the paper consists of four sections. The first, presents a concise review of the literature which inspired the authors' research. The second part introduces a methodology applied, including: a research design, hypotheses, as well as response and explanatory variables used to test the hypotheses. The third section presents results of the empirical analysis. The final part summarizes findings and discusses limitations of the research as well as presents its future extension opportunities.

\section{Literature Review}

A company is unlikely to survive in a contemporary market if it does not consider human capital as its key success factor (see Mayo 2001, Armstrong 2008; Pennig and Traut 2009). An organization will not build its competitive advantage being unaware of how to manage that capital, either. Understanding relations between corporate and individual objectives and, consequently, individual and corporate performance, has become a vital issue in performance management. Such a view on performance management links it closely to the strategic human resources management, which focuses on integrating organizational objectives with HR policies, in order to execute a business strategy and fulfil a mission of an enterprise effectively (Baird and Meshoulam 1988; Lengnick-Hall and Lengnick-Hall 1988; Wright and McMahan 1992; Wei 2006; Inyang 2010). Employees' awareness of their contribution to a corporate strategy stimulates involvement in meeting long- and short-term objectives, and consequently triggers increase in a value of an enterprise and its market position (Inyang 2010). This refers particularly to SMEs at their growth phase.

In the context of linking strategic human resources management with performance management a leadership style, understood as a choice of measures to influence employees and stimulate performance-oriented actions, needs to be considered. In particular a difference between autocratic and democratic approach is vital. The two opposing styles are distinguished based on ways in which leaders 
set directions for development, work out and execute plans or interact with their subordinates.

The autocratic leaders make vital decisions on their own, whereas democratic ones look for consensus, consulting decisions with subordinates (Cellar et al. 2001, p. 63; Maloş 2012, p. 421). The first also prefer to establish strict regulations, control processes and remain in formal, professional relationships with their subordinates, while the other provide guidance, empower subordinates to make the best use of their competencies and talents, and prioritize social aspects of group work (Maloş 2012, pp. 421-423). They also reward employees for commitment and prefer not to penalize mistakes but work on problems instead. Empowered employees feel more responsible for meeting goals (İnandi, Uzun, Yeşil 2016, p. 194).

The autocratic leadership style does not instill learning mentality which is crucial to stimulate proactive attitudes among employees (Sauer 2011). A lack of consultation with subordinates may cause that opportunities are missed and risks are underestimated. Democratic leaders, on the contrary, involve employees in discussion on business prospects and consultations on emerging and foreseen problems. Consequently, employees are more committed to their work and willing to release creativity as a results of the confidence entrusted. The democratic approach stimulates also quality assuring behaviors (Cunningham, Salomone, Wielgus 2015, p. 34).

Nonetheless, the autocratic leadership should not be showed in bad light only. Autocratic leaders give their subordinates clear and short instructions on what to do and how to do it. This helps to perform tasks effectively, solve identified problems, and meet targets or deadlines, in particular when time is a critical factor (Sauer 2011; Cunningham, Salomone, Wielgus 2015, p. 34). Consequently, performance may increase on a short-run (İnandi, Uzun, Yeşil 2016, p. 194). On the other hand, democratic leadership has a major disadvantage. Time required to move onwards is extended. To counterbalance that adverse effect, democratic leaders should aim at developing highly-motivated, but smaller teams (Fiaz et al. 2017, p. 147), what is a good option for small and medium sized companies.

Unfortunately, in smaller businesses, the autocratic leadership style is much more frequent than the democratic one. It is an unwelcome situation, since an intellectual stimulation is essential in SMEs, where leaders have a closer contact to all employees and can effectively encourage employees' creative thinking and implementing innovative ideas. Moreover, SMEs are not burdened with formalized structures and procedures which are often found in large organizations. Therefore, they may focus on unstandardized solutions offering a better adjustment to the changing business environment. Team-working in small groups, where individual members become closer to one another, causes that employees feel committed to performing tasks, since their efforts and performance may be easily noticed and appreciated.

Leadership styles play a very special role in SMEs for few more reasons. Firstly, SMEs are exposed to a fierce competition for talented employees both between companies of that size and the large ones. Retention of qualified 
employees depends to a significant degree on quality of work life. It was evidenced that the way in which leaders act influences directly work conditions appreciated by employees, such as autonomy of work on the one hand, and good cooperation between people on the other one (Nanjundeswaraswamy, Swamy 2015, p. 75). Secondly, it is important to point out that in SMEs with a flat organization hierarchy, comparing to large enterprises, an influence of leaders on subordinates, both positive and negative, is amplified (Ogarcă, Crăciun, Mihai 2016, p. 284). The major advantage of empowering employees in SMEs is seen in higher sales growth rates and increasing professionalism in the company (Wang, Poutziouris 2010, p. 345). Thirdly, democratic leadership style is particularly recommended in case of innovative organizations or projects which require cooperation between various units of an organization (Mohiuddin 2017, pp. 26-27), and therefore, it should be considered both in start-ups and in technologically intensive companies. Fourthly, SMEs, being more exposed to changes in their business environment, experience positive and negative influences of participative management systems. On the one hand, they increase adaptability, innovativeness and knowledge sharing. On the other one, they reduces clarity of roles and procedures and may disturb in setting long-range plans (Psychogios, Garev 2012, p. 18).

Leadership is critical in a changing business environment, where small and medium sized companies operate, and even more when changes are amplified by transformations of a whole economy, like in case of post-socialistic countries which entered the Common Market. Moreover, SMEs cannot build their advantages over larger companies on the basis of resources. Their competitive advantage lies in flexibility and adaptation to customers' needs and market condition. Change processes which cover the entire organization or its parts requires transformational leadership.

The concept of transformational leadership which was developed by Burns (1978) and extended by Bass (1985) is close to the democratic leadership style. Transformational leaders inspire employees who become capable of changing their attitudes and are motivated toward goal achievement. To make it happen, leaders apply four behavioral attitudes which refer directly (individual consideration) or indirectly (intellectual stimulation, inspirational motivation, idealized influence) to the participative management style.

The individual consideration reflects a focus on personal contribution of employees, where a leader through coaching, mentoring, fostering and challenging instills a feeling of belonging to the organizational community, and thus stimulates motivation and responsibility for goal achievement. Moreover, leaders who demonstrate such an attitude toward subordinates enhance two-way communication and become more sensitive to ideas and proposals coming from staff members (Bass and Riggio 2006; Detert and Burris 2007). A process of intellectual stimulation aims at releasing 'outside the box' way of thinking which produces new solutions to old problems (Bass 1998; Arnold and Loughlin 2013).

The inspirational motivation may appear when a business vision is communicated with an adequate optimism to employees. It should be emphasized that an inspiration is induced both by comprehensive, consistent visions and by 
strategic awareness which facilitates a conversion of strategic objectives into short-term operating goals. Leaders have idealized influence when they are able to set a sense of business activity, and as a result they become "a role model whom followers aspire to emulate" (Arnold and Loughlin 2013).

In the aforementioned literature context, the authors' research on linkages between participative management and performance-based remuneration systems, as well as employees' satisfaction from rewarding add three important elements to the scientific discussion. Firstly, it should help to identify whether involvement of employees in planning and in discussion on corporate and individual performance is a precondition for developing performance-based rewarding strategies. Secondly, the study intends to prove that understanding one's own contribution to strategic and operational goals makes employees willing to be rewarded for effects. Finally, the research should demonstrate that in SMEs, where managers are much more attainable to employees, and vice versa, and where managing owners are much more personally involved in running businesses, it is better to take a team approach rather than to manage a business autocratically.

All the said issues are vital from the perspective of Polish business practices, where participative management style was never prioritized, where control did not evoke positive associations, where employees were not used to be evaluated and rewarded on results, and where the staff member were unwilling to take responsibility and to innovate. Thus, the study may show that the heritage of the socialism era to be found in social attitudes - autocratic acting - has lost on importance and given way to a more democratic - leadership-based - corporate business culture.

\section{Methodology}

\section{Research Design}

The empirical results presented in the paper are based on the study conducted by the authors at the turn of 2013 and 2014. The examination included 179 organizations operating in Poland including: 93 SMEs and 86 large companies.

In order to guarantee comparability of results obtained, we developed a standardized research form which consisted of three parts. The first one covered basic characteristics of examined organizations (their legal status, foundation year, total employment, sales revenue, a business domain, a geographical area of operation, and a capital structure). The second one included 16 open questions related to planning, control, reporting and communication processes. The final three questions validated collected information by describing positions, workprofiles and experience of the interviewees as well as any sources of information they referred to.

It should be added that the structure of respondents from examined companies according to their functions was as follows: production, quality management, marketing, sales and logistics departments $(38,4 \%)$, finance, accounting, and 
management control units $(27,5 \%)$, back-office, HR and legal departments $(21,7 \%)$, operational management $(6,5 \%)$, IT, R\&D and other specialized units $(5,8 \%)$. In the statistical analyses, though, each company was treated as one research object.

Table 1 characterizes examined organizations, considering their sizes and activity domains. The number of companies in each class (integer numbers) and shares in the whole sample (percentages) are shown. Dominating values in each subgroup (rows) are presented with bold print.

Table 1. Composition of the Examined Sample $(n=211)$

\begin{tabular}{|l|c|c|c|c|c|}
\hline Subgroup Size & $\begin{array}{c}\text { micro } \\
\text { enterprises }\end{array}$ & $\begin{array}{c}\text { small } \\
\text { enterprises }\end{array}$ & $\begin{array}{c}\text { medium } \\
\text { enterprises }\end{array}$ & $\begin{array}{c}\text { large } \\
\text { enterprises }\end{array}$ & $\begin{array}{c}\text { Tot } \\
\text { al }\end{array}$ \\
\hline $\begin{array}{l}\text { farming and food } \\
\text { industry }\end{array}$ & - & $3(18.8 \%)$ & $6(37.5 \%)$ & $\mathbf{7 ( 4 3 . 8 \% )}$ & 16 \\
\hline $\begin{array}{l}\text { industrial } \\
\text { production }\end{array}$ & $3(7.3 \%)$ & $7(17.1 \%)$ & $3(7.3 \%)$ & $\mathbf{2 8 ( 6 8 . 3 \% )}$ & 41 \\
\hline construction & $6(28.6 \%)$ & $\mathbf{8 ( 3 8 . 1 \% )}$ & $5(23.8 \%)$ & $2(9.5 \%)$ & 21 \\
\hline trade and logistics & $5(14.3 \%)$ & $9(25.7 \%)$ & $5(14.3 \%)$ & $\mathbf{1 6}(\mathbf{4 5 . 7 \% )})$ & 35 \\
\hline ICT sector & - & $4(28.6 \%)$ & $1(7.1 \%)$ & $\mathbf{9 ( 6 4 . 3 \% )}$ & 14 \\
\hline $\begin{array}{l}\text { finance and } \\
\text { insurance }\end{array}$ & $6(15.4 \%)$ & $5(12.8 \%)$ & $2(5.1 \%)$ & $\mathbf{2 6 ( 6 6 . 7 \% )}$ & 39 \\
\hline services & $\mathbf{1 9 ( 3 2 . 2 \% )}$ & $12(20.3 \%)$ & $11(18.6 \%)$ & $17(28.8 \%)$ & 59 \\
\hline Total & 30 & 34 & 29 & 86 & 179 \\
\hline
\end{tabular}

Source: own elaboration

When a structure of the research sample is analyzed a similar number of objects belonging to micro, small and medium-sized groups (30, 34 and 29, respectively) should be noted, which was in total comparable to the number of large enterprises (86 objects, $48.0 \%$ of the examined group). Although this composition does not reflect the actual profile of the Polish economy, where microenterprises are dominant, sufficient numbers of objects in each class enable comparisons of reward strategies and management practices between organizations of different sizes.

Respecting business areas, the examined companies were grouped in seven domains: farming and food industry, industrial production, construction, trade and logistics, information and telecommunication technologies (ICT sector), finance and insurance, and services. The largest categories included: services (59 objects), industrial production (41 objects) and finance and insurance (39 objects). SMEs made a considerable share of construction and service sector (90.5\% and $71.2 \%$ respectively), whereas large enterprises dominated industrial production $(68.3 \%)$, finance and insurance $(66.7 \%)$ and ICT $(64.3 \%)$ sectors.

\section{Development of Hypotheses}

In this part of the paper three hypotheses are formulated. They link participative management - being a manifest of a democratic leadership style with remuneration strategies developed in enterprises, in particular those 
belonging to the SME sector, and with the evaluation of those strategies by employees. Before the hypotheses are presented, it is important to explain premises on which they were built, including prior studies of the authors, macroeconomic situation and a broader literature context.

The following two opinions on reward strategies were expressed by interviewed employees from: (\#1) a large Polish company and (\#2) a microenterprise operating in Poland (Dyczkowska and Dyczkowski 2012).

The employee \#1: "Annual rewards are paid when a reporting period is closed. Employees are also offered individual bonuses, paid each month. Annual rewards are contingent on goals fulfilment, whereas monthly individual bonuses are given to employees for their contribution in teamwork. Employees are acquainted with a total value of bonuses granted and a list of staff members who were awarded bonuses for goal fulfilment. I evaluate both the transparency of the rewarding process and amounts of bonuses very well."

The employee \#2: "The company has developed its motivational system poorly. Salaries are fixed as a rule. Occasionally better corporate performance causes higher pay. I think it is a mistake that the company has not introduced bonuses dependent on results. Effectiveness of employees is strongly associated with their mobilization to work."

The differences in structuring remuneration systems exemplified in the two quoted statements may be linked to the general structure of remuneration in Poland.

Table 2.Structure of Gross Monthly Earnings

\begin{tabular}{|c|c|c|c|c|}
\hline $\begin{array}{c}\text { Remuneration } \\
\text { component }\end{array}$ & $\begin{array}{c}\text { Average } \\
\text { amount } \\
\text { [PLN] }\end{array}$ & \begin{tabular}{|c|} 
Availability to \\
employees \\
{$[\%]$}
\end{tabular} & $\begin{array}{c}\text { Average } \\
\text { contribution } \\
{[\text { PLN] }}\end{array}$ & $\begin{array}{c}\text { Average } \\
\text { contribution } \\
{[\%]}\end{array}$ \\
\hline $\begin{array}{l}\text { Average monthly } \\
\text { gross earning } X \\
2012 *\end{array}$ & 3895.72 & 100.0 & 3895.72 & 100.0 \\
\hline flat wage and salary & 2833.81 & 100.0 & 2836.77 & 72.7 \\
\hline bonuses for shifts & 261.61 & 12.3 & 32.21 & 0.8 \\
\hline $\begin{array}{l}\text { statutory prizes and } \\
\text { bonuses }\end{array}$ & 694.04 & 29.9 & 207.73 & 5.3 \\
\hline $\begin{array}{l}\text { optional prizes and } \\
\text { bonuses }\end{array}$ & 516.19 & 47.0 & 242.86 & 6.2 \\
\hline other components & 817.34 & 52.0 & 425.46 & 11.0 \\
\hline overtime bonuses & 534.97 & 15.5 & 83.01 & 2.2 \\
\hline fees & 2760.91 & 0.4 & 11.06 & 0.4 \\
\hline $\begin{array}{l}\text { annual extra salaries } \\
\text { in budgetary entities }\end{array}$ & 296.48 & 18.5 & 54.91 & 1.4 \\
\hline $\begin{array}{l}\text { payments from profit } \\
\text { and balance surplus }\end{array}$ & 286.12 & 0.6 & 1.72 & 0.0 \\
\hline
\end{tabular}

Source: Structure of wages..., 2014, p.42 
The table 2 presents a structure of salaries in Poland, including private and public sectors. The first numeric column shows an average monthly amounts of various remuneration components, including: flat payments, bonuses, fees (received by authors, artists etc.), as well as extra annual salaries in the public sector or payments from corporate profits. It should be mentioned that performance related bonuses analyzed in the authors' research are reflected mostly by the categories of 'statutory' or 'optional prizes and bonuses'. The difference is, that the first are offered when strictly defined conditions, included in a bonus systems, are met, whereas the other depend on managers' decisions. Both components covered on average $24.5 \%$ and $18.2 \%$ of flat salaries respectively. Though, the bonuses were not available to all employees. Statutory bonuses were offered to $29.9 \%$ of employees and optional ones to $47.0 \%$ of the labor force. For the research sample analyzed by the authors various performance related bonuses were used in $72.1 \%$ of large companies and in $54.7 \%$ of SMEs, what seems to correspond well with general data for Poland. Considering amounts and availability of bonuses to employees it could be concluded that performance related bonuses made $11.5 \%$ of an average monthly salary only.

Moreover, one should consider that average pays in companies employing between 2.000 and 5.000 employees in comparison to micro or small companies were higher by $205 \%$. The latter group offered salaries at a level of $74.7 \%$ of those in the public sector. This shows that pays in smaller companies in Poland were uncompetitive.

Due to the aforementioned observations that Polish companies rarely include performance-related factors in their remuneration systems and that SMEs offer lower pays to their employees, there appeared a conviction that organization of work must have been linked both with remuneration strategies and satisfaction of employees.

Moreover, responses of employees from large and microenterprises (the same as quoted earlier) in the following three areas: strategic planning and communication of a strategy, participation in goal-setting processes, and use of managerial feedback indicated differences in leadership styles between companies of various sizes. The first was a democratic leader's style who showed directions, but at the same time encouraged employees to find better ways to cope with their routine tasks, whereas the other represented the autocratic style of person who knows all questions and all answers, and did not have to consider opinions of subordinates.

The employee \#1 on strategic planning: "Employees are acquainted with a strategy and long-term objectives. Several times a year employees participate in meetings dedicated to discussion on current changes which might affect long-term plans. I assess positively both long-term planning and implemented changes which aim at completing long-term objectives. Regular and smooth communication of superiors with subordinates facilitates that process, since employees have an opportunity to express their opinions in key matters as well as to propose certain changes." 
The employee \#2 on strategic planning: "I think that the lack of long-term planning have a negative impact on business activity. The organization does not act properly. It is difficult to set adequate direction of actions. Risk situations, problems and mistakes may appear and threaten an existence of the organization in the future."

The employee \#1 on goal-setting: "Although operational goals are formulated by top management, lower level managers together with their subordinates are accountable for budget performance. Each employee is supposed to set at least three individual goals. The individual goals should be in line with strategic objectives, and measurable. Moreover, the organization investigates employee satisfaction each year. The results are used to formulate 'soft-goals', which aim at personal development of staff members."

The employee \#2 on goal-setting: "Employees should be informed about expectations of their superiors if they are expected to contribute to realization of short-term goals."

The employee \#1 on managerial feedback: "At least every quarter of a year each team organizes a meeting which is dedicated to sum up and compare financial results achieved in relation to other units. An assessment of individual performance takes place at least every half a year. Feedback received is always discussed by an employee in question and their superior (or a coach). Since meetings are convened periodically and information is commonly available for each staff member, personnel is well oriented in corporate performance, what allows better strategy comprehension and better adjustment to changes. Individual meetings with superiors contribute to quicker reactions in case of any problem. Although such communication requires a lot of time and dedication from direct superiors and higher level managers, it pays off in the future, since the organization has its personnel well informed, strategically aware and change-oriented."

The employee \#2 on managerial feedback: "From time to time employees take part in a briefing where a level of goal achievement is assessed. However, such briefings are not regular. Regular meetings which aim at presenting corporate performance are organized for managers. I think that superiors should talk about individual achievements with employees. It would positively influence work and facilitate a common comprehension between particular organizational levels."

The presented examples of how leadership styles affected relationships in the work environment, and thus a job satisfaction, correspond well with other research. For instance, it was evidenced that autocratic leadership negatively affects effectiveness of leaders, and thus future motivation of employees (Cellar et al. 2001, pp. 65-66), by amplifying the feelings of frustration and anger (Fiaz et al. 2017, p. 147) and reducing creativity (İnandi, Uzun, Yeşil 2016, p. 194), unless subordinates themselves are uncooperative and distrustful (Cellar et al. 2001, p. 70). The latter, however, implies dysfunctional group relationships.

On the other hand, it is important to point out, that not always increasing employees participation in decision making processes contributes to a better performance of a company. It turns out that insufficient skills of a leader are 
much more detrimental to organizational performance in democratic leadership style, that in the authoritative one (Odiri 2016, pp. 291-292).

Nonetheless, the authors observe a research gap of direct linking participative management - which embodies features of democratic leadership - with a scope of applying performance-related remuneration systems and satisfaction of employees with such a solution in SMEs. To fill in that gap an example of a post-transition country, with observed changes in leadership styles appears relevant. This choice may be substantiated with the analysis of motivation systems in Romania, a country with a similar road to the market economy to Poland, which suggested the following improvement strategies (Marin 2012, pp. 806809): CEO's involvement in motivational process, motivational environment in an organization including its links to stakeholder, delegating responsibilities, participatory management, rewarding system in match with achievements, developing psycho-sociological competencies in a company - the three of which are addressed in this paper.

Considering all the forgoing macroeconomic data, signals derived from the pilot research in 2010, and a broader literature context, the three hypotheses will be tested in the paper.

H1: Employees involved in managerial activities prefer performance-related remuneration systems.

$\mathrm{H} 2$ : Employees involved in managerial activities are more satisfied with their remuneration.

H3: SMEs operating in Poland, do not benefit from involvement of employees in managerial activities, and thus are perceived as less attractive employers than larger companies.

\section{Description of Response and Explanatory Variables}

In order to validate the hypotheses in this study we recognized various approaches to reward strategies, including: merit pays, individual bonuses, incentives contingent on corporate performance as well as long-term pay rises or promotions for work effects, and fixed pays. The related response variable: reward strategy (REW) was quantified as presented in table 3.

The second dependent variable: evaluation of reward strategy (ev_REW) measures employee satisfaction with rewarding systems and salary levels in an enterprise. Respondents evaluated the existing solution using 7-point scale. In that way descriptive evaluations of reward strategies were supported with a quantitative assessment. 
Table 3.Description of Response Variables

Reward strategy (REW)

Question: Are employees' pays related to their individual objectives or those to be met by departments of the whole company?

\begin{tabular}{|c|l|c|}
\hline No. & Answer options & Score \\
\hline 1. & Merit-based compensations & 5 \\
\hline 2. & Bonuses for individual performance & 4 \\
\hline 3. & Bonuses for corporate performance & 3 \\
\hline 4. & Pay increments or promotion for work effects & 2 \\
\hline 5. & Remuneration should be linked to business objectives & 1 \\
\hline 6. & Fixed pays & 0 \\
\hline $\begin{array}{l}\text { Evaluation of reward strategy (ev_REW) - Evaluation of satisfaction from rewarding, } \\
\text { with a use of a 7-point scale }\end{array}$ \\
\hline
\end{tabular}

Source: own elaboration

Measurement of participative character of management was done using a compound explanatory construct: participative management (PAR), which covered the following three variables: strategic awareness (SAW), goal-setting process (GSP) and managerial feedback (MFE) (see table 5).

Such an understanding of the participative management is not isolated from prior studies. Kim (2002) tested hypotheses related to the above mentioned areas. She recognized three circumstances in which employees were more likely to express higher level of satisfaction with their job. The first, referred to employees' perception of strategic planning. The second one was related to employees' trust in participative management style of their superiors, whereas the last one reflected employees' opinion on how effective communications with their superiors was (Kim 2002).

The first of the three aforementioned constructs: strategic awareness plays a crucial role in enhancing competitive advantage of enterprises, particularly those acting as decentralized business units. Intangible values, including: knowledge, capabilities and relationships are co-created by lower level employees, who are responsible for putting a strategy into action (Kaplan and Norton 2000). Therefore, there arises a need for an effective communication of a strategy to employees on each level of an organizational hierarchy. Moreover, strategic awareness together with a high degree of empowerment enhances employees' motivation and commitment to a corporate strategy.

Kim (2002) stated that a person who is involved in strategic decision-making is able to influence its working environment in the widest possible manner. Consequently, the context in which strategies are formulated may moderate a relationship between participative decision-making and job satisfaction (Daniels and Bailey 1999; Kim 2002). In addition, Lawler (1986) and Ledford (1993) listed the four drivers of successful team-working. First of all, employees should be provided with adequate information. Secondly, they should be entitled to make decisions and, thirdly, be remunerated properly for meeting objectives. Finally, they should have requisite conditions to develop their competencies (Lawler 1986; Ledford 1993; Scott and Tiessen 1999). 
Table 4. Structure of the Participative Management (PAR) Variable

\section{Strategic awareness (SAW)}

Question: Does an organization draw up strategic plans and are employees made familiar with them?

\begin{tabular}{|c|l|c|}
\hline No. & Answer options & Score \\
\hline 1. & Strategic plans are drawn up for each area of business activity & 5 \\
\hline 2. & A strategy is known to employees & 4 \\
\hline 3. & Strategy is known exclusively to managers & 3 \\
\hline 4. & There are some general long-term plans developed & 2 \\
\hline 5. & Planning refers to one-year or even shorter periods & 1 \\
\hline 6. & An organization performs day-to-day activities & 0 \\
\hline
\end{tabular}

Goal-setting process (GSP)

Question: Does an organization fix operational goals for particular departments, teams or individual employees?

\begin{tabular}{|c|l|c|}
\hline No. & Answer options & Score \\
\hline 1. & Employees participate in a goal-setting process & 5 \\
\hline 2. & $\begin{array}{l}\text { Goals are established by senior management in a form of a plan to } \\
\text { execute }\end{array}$ & 4 \\
\hline 3. & Superiors establish targets for the nearest period & 3 \\
\hline 4. & Superiors express only general expectations towards employees & 2 \\
\hline 5. & Employees are expected to perform their duties & 1 \\
\hline 6. & Employees do not have a scope of their duties defined & 0 \\
\hline
\end{tabular}

\section{Managerial feedback (MEF)}

Question: Are there any meetings convened where organizational performance is discussed?

\begin{tabular}{|c|l|c|}
\hline No. & Answer options & Score \\
\hline 1. & $\begin{array}{l}\text { Employees participate in regular meetings with a management or } \\
\text { superiors }\end{array}$ & 5 \\
\hline 2. & Superiors discuss with employees their performance & 4 \\
\hline 3. & $\begin{array}{l}\text { There is an annual meeting with a presentation of performance } \\
\text { convened }\end{array}$ & 3 \\
\hline 4. & There are some briefing sessions for employees organized & 2 \\
\hline 5. & The meetings include management only & 0 \\
\hline 6. & There are no such meetings organized & \\
\hline
\end{tabular}

Source: own elaboration

A degree of participative management was also conditioned in the authors' study by an involvement in goal-setting. Although an impact of participative planning on job satisfaction was measured in several prior studies which evidenced that the connection existed (Spector 1986; Fisher 1989), later findings suggested that said relation was nonlinear or even inconsistent, and depended on individual and situational conditions (Daniels and Guppy 1994; Cotton 1995; Daniels and Bailey 1999). In the authors' investigation the planning approaches reflected the four most typical situations (see table 4): participative planning (answer 1), top-down planning (options 2-3), rudimentary planning practices (answers 4-5) and ad hoc organization of work (option 6).

The last component of participative management: managerial feedback reflects integration of employees in discussion on corporate performance. Such 
debates are not expected to include only briefings where annual results are presented, but are supposed to let employees express their opinions. Following Detert and Burris (2007), even though employee voice "may challenge and upset the status quo of the organization and its power holders, [it] is critical to organizational well-being". It is necessary, therefore, to create conditions where benefits of speaking up are not outweighed by risks which result from a complexity of human relations within an organization (Detert and Burris 2007; Pitkänen and Lukka 2011). Emmert and Taher (1992).Employees who positively assess their job environment and who communicate smoothly with their peers and superiors should demonstrate higher job satisfaction than individuals with negative perceptions of both.

\section{Findings and Implications}

This part of the paper presents empirical results of the research on Polish SMEs in comparison to large enterprises. First of all, remuneration strategies and their acceptance among employees will be analyzed. The results for SMEs are visualized in figure 1 . Next, the three factors which depict participative management are presented. The results for SMEs can be found in figures 2-4, respectively.

\section{Rewarding Systems}

When remuneration systems in Polish SMEs are considered, it can be noted (see figure 1) that $68.8 \%$ of companies declared using fixed pays. In $43,0 \%$ of companies neither merit-related remuneration, nor bonuses, not even performance related promotions systems were installed. Such a situation should be perceived as a negative one, because in smaller companies individual employees' contribute more to an overall corporate performance than in large ones.

Satisfaction with fixed pays systems was also low, with the average score of 3.5 in a 7-grade scale (where 3 meant a slightly negative evaluation and 4 a neutral one). Interestingly, only in $9.7 \%$ of employees declared firmly that fixed payments were inappropriate and that remuneration in their companies should have been linked to performance. In $20.4 \%$ of SMEs a mixed system was used, with a fixed basic payment and various bonus schemes. This remuneration system was seen as neutral (with the satisfaction rate of 4.0). Finally, a performance based rewarding was used in $30.1 \%$ of enterprises. Of all performance related remuneration options, individual bonuses were considered most welcome, topping even merit-based compensations. This observation corresponds with findings of other researchers that, even though merit-based compensations are strongly motivating, since employees are rewarded directly for their individual effects, individual performance-related bonuses are preferred both by employers and employees due to their higher flexibility (Sturman and Short 2000; Park and Sturman 2009; Milkovich and Newman 2005). 
Figure 1. Reward Strategy in SMEs

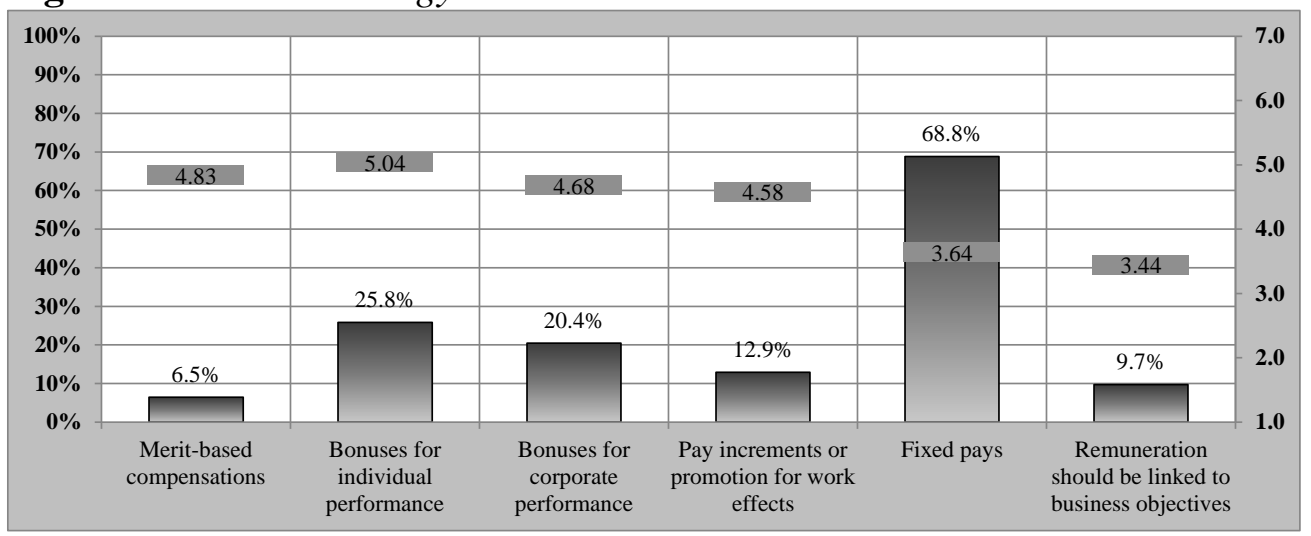

* multiple answers could be selected (total does not equal 100\%)

Source: own presentation

Bonuses related to corporate performance turned out to be less desired. It can be concluded - based on descriptive answers included in research forms that such bonuses were lower, since performance targets (or sales targets) were set at very demanding levels. Employees believed also that they had little influence on corporate performance, and thus the motivation effect was seen problematic. The results also showed that employees demonstrated less trust in pay increments and promotions related to their performance. That stemmed from poor pay increment prospects in many companies due to unstable market situation.

When the abovementioned results for SMEs were confronted with those obtained in a group of large companies, the following conclusions could be drawn. First of all, even though fixed pays were also the most frequently referred option in large companies (57.0\% of cases), the differences between that rewarding strategy and other ones were less apparent. Bonuses for individual performance - the second most popular solution - were found in $40.7 \%$ of large companies. When all performance-related compensation methods were put together, it became visible that $72.1 \%$ of large enterprises offered incentives for individual or team performance (in comparison to $54.7 \%$ in case of SMEs).

Considering satisfaction from pays, it turned out again that fixed pays were the least appreciated. Mixed systems were assessed as positive, whereas bonuses linked to individual performance were the most desired.

To sum up, Polish SMEs seemed to develop performance related rewarding systems less frequently than large companies. The satisfaction with salaries grew together with a company size, reaching 3.7 for microenterprises (a negative assessment), 4.2 for small companies, 4.3 for medium-sized ones and 4.5 in case of large enterprises. Moreover, the satisfaction from remuneration in micro companies was even lower than that in the public sector - examined by the authors in a separate study. 


\section{Participative Management}

\section{$\underline{\text { Strategic Awareness }}$}

The first analyzed factor - strategic awareness - indicated whether strategic plans were formulated and employees kept informed about those plans in the examined enterprises (fig.2).

Figure 2.Strategic Awareness in Polish SMEs

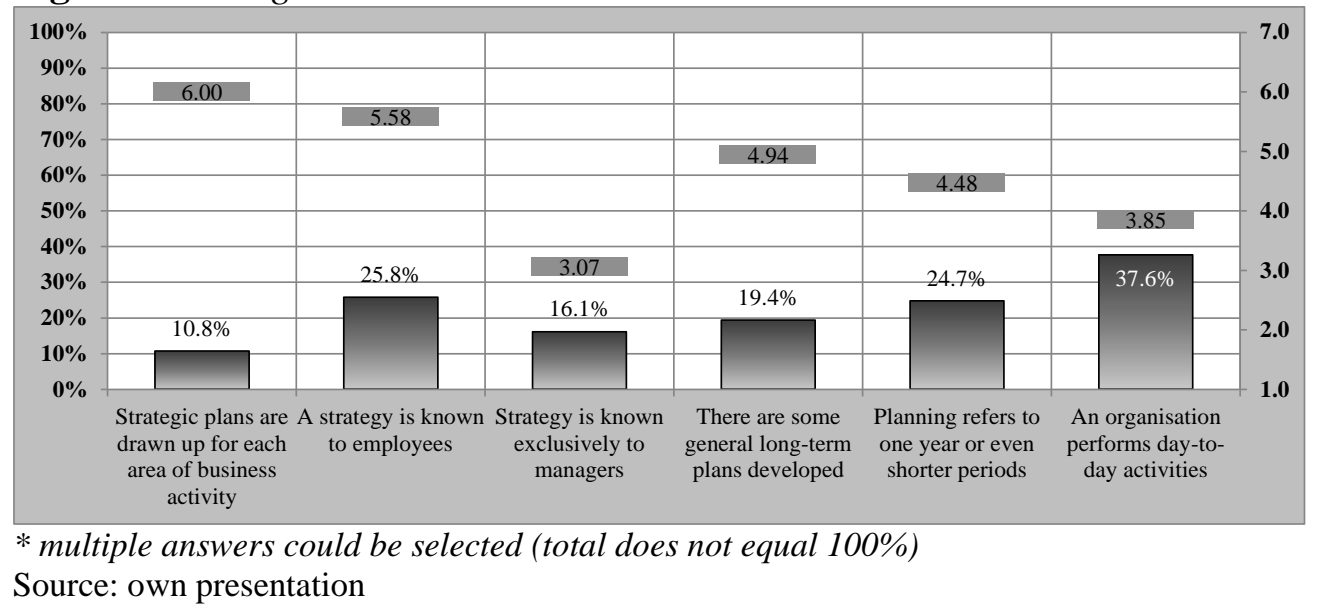

The first two answer options reflected situations when employees were aware of strategic plans either for each area where an organization operated or for a company as a whole. Those two scenarios were reported together by $28.0 \%$ of SMEs. Making employees familiar with strategic plans of a company proves that managers trust in their staff, what intensifies employees' affiliation to the company. It is an auspicious signal for a future business development. The aforementioned scenarios were appreciated by employees who assigned satisfaction scores of 6.0 and 5.6 to them respectively. It should be added, that in $62.8 \%$ of large companies employees were fully aware of corporate strategies. The satisfaction level for large companies reached 5.3, what may suggest that strategic planning was more obvious in that group of organizations.

The third option exhibited a situation where employees were conscious of an existence of a strategy in a company, but that strategy was not revealed to anyone but the managers. Such a scenario was reported in $16.1 \%$ of SMEs and in $31.4 \%$ of large companies. Interestingly, in the latter group that situation was perceived as neutral, whereas is SMEs it was seen as negative. Based on descriptive answers it could be concluded that in some large companies employees felt that strategic issues should be left to top managers, since such topics went beyond activity scope of regular employees. In smaller enterprises, lack of information was associated with an insecure future, and made the staff feel uncomfortable.

Taking all the three aforesaid answer options into consideration, it can be stated that strategic plans were developed by $40.9 \%$ of SMEs and $86.0 \%$ of large companies. If also the fourth scenario (representing 'some general long- 
range plans') was included, it appeared that over a half $(51.6 \%)$ of SMEs considered issues reaching beyond current operations in their planning. For large companies this was $91.9 \%$, what showed a huge gap in strategic thinking between Polish SMEs and large companies.

Finally, an option when enterprises performed day-to-day operations only was selected by $37.6 \%$ of SMEs. In majority of cases this was the only answer given. That meant that in every third Polish SME not only employees remained unaware of a corporate strategy, but even managers or owners seemed not to look to far ahead. That temporariness was perceived as slightly negative.

\section{$\underline{\text { Goal-setting processes }}$}

Beside the strategic awareness, methodologies of formulating operational goals were analyzed (fig. 3). In most of cases employees of SMEs felt they were expected to perform their duties. In many cases the said answer reflected a situation when employees performed routine and repeatable tasks with no specific goals or targets defined. Employees from $24.7 \%$ of SMEs reported that they were neither given formal goals, nor tasks to be accomplished. Even general expectations were not expressed by their superiors. Surprisingly, the described situation was treated as a positive one, with a possible explanation that employees felt they knew what they were doing and did not expect anything positive from scrutinizing their work by managers. In case of large companies employees reported also frequently they were expected to fulfil they duties. Though, only in $9.3 \%$ of companies that was the only way to organize work. Moreover, such a situation was seen as a negative one.

Figure 3. Goal-setting Process in Polish SMEs

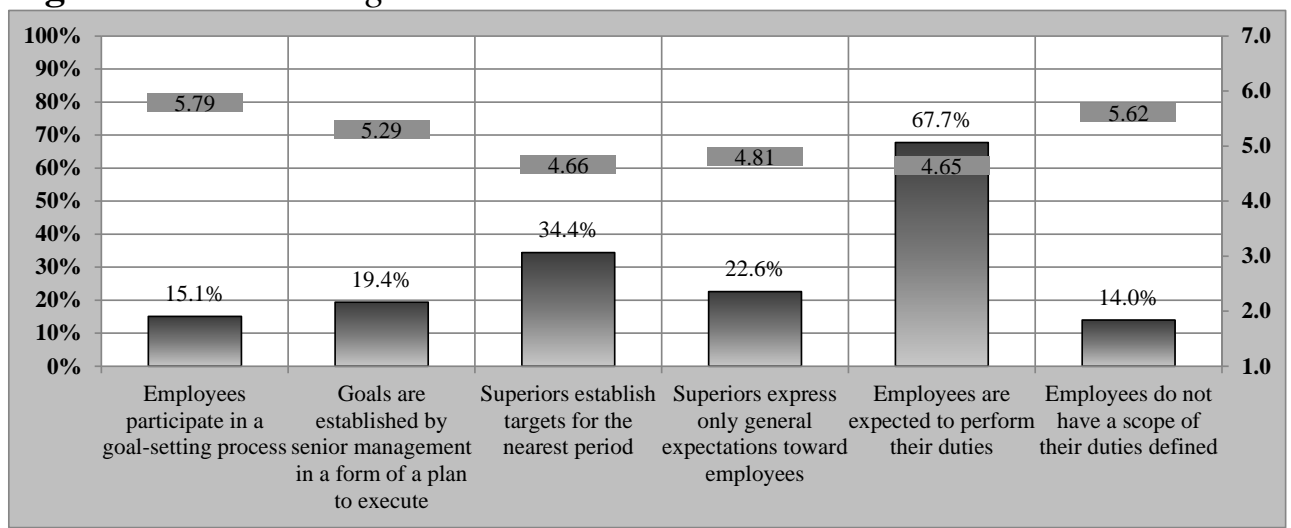

* multiple answers could be selected (total does not equal 100\%)

Source: own presentation

Considering formal ways of establishing goals in SMEs, the most frequent situation was the one when superiors set targets for the nearest periods (reported in $34.4 \%$ of cases). This was a level similar to the one found in large companies. Formalized plans set by managers were found in $19.4 \%$ of SMEs. That was much lower a share than in case of large companies $(55.8 \%)$. Finally, participative planning was reported by $15.1 \%$ of SMEs, which was again much lower a share 
than the one for large enterprises (30.2\%). In both groups, though, that situation was assessed positively. Taking all the three formalized ways of planning together, it turned out that in over a half of SMEs $(55.9 \%)$ and in $80.2 \%$ of large companies employees had tangible goals or targets to refer to. That implied a possibility to apply rewarding systems based on performance.

Finally, it should be added that in $14.0 \%$ of SMEs and in $18.6 \%$ of large companies, employees had no precise scope of duties defined. Surprisingly, those situations were considered as positive. The descriptive answers showed that a possibility to define one's own tasks lead to higher effectiveness and efficiency of work and, consequently, to extra rewarding for performance.

\section{Managerial feedback}

The final indicator of participative management analyzed was whether there were meetings for employees organized where corporate performance was discussed (fig. 4). Such a situation indicated that managers found employees as important contributors to a success of a company, and not just as performers of orders.

Figure 4. Managerial Feedback in Polish SMEs

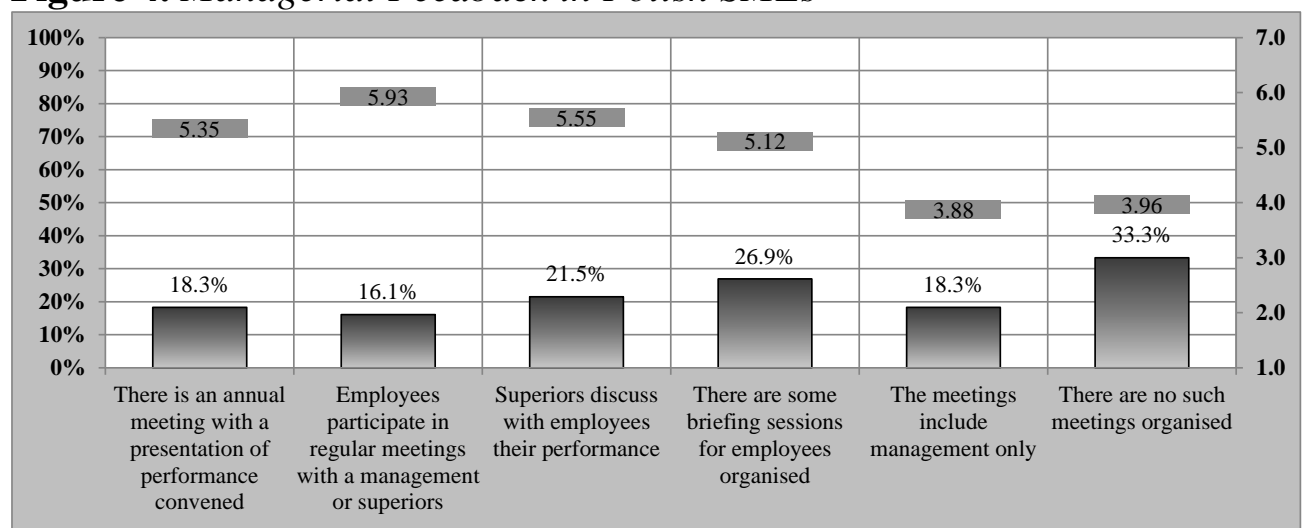

* multiple answers could be selected (total does not equal 100\%)

Source: own presentation

Briefing sessions for employees, organized when there were urgent issues to be communicated, tuned out to be the most frequent form of managerial feedback in SMEs. Such meetings were convened in order to initiate actions, rather than to inform on results. Their formats, duration and information scope differed. In certain cases one-way communication was used, in other employees were allowed to ask questions and could expect answers. That latter form of communication was found satisfactory by employees. In large companies briefing sessions were popular, but not prevalent. Though, they were considered the most appropriate.

In $34.4 \%$ of SMEs there were annual or even more frequent meetings with managers organized where corporate performance was addressed. The annual meetings were perceived as the most beneficial. Considering all the aforesaid answer options, it can be said that over a half of SMEs integrated their employees 
in a discussion on business performance. For large companies that share reached $73.3 \%$.

On the other hand in $18.3 \%$ of Polish SMEs performance related meetings were convened in management circles only. This situation was assessed as slightly negative. In case of large companies the share rose to $33.7 \%$. Obviously, the larger the company was, the less practical it would be to integrate employees in all discussions. Though, due to well-developed internal communication frameworks employees did receive summaries from their superiors. That is why no exclusion feeling was observed.

Finally, in every third SME no performance related meetings were held, what evoked mixed feelings among employees. In some cases employees wanted to know more, whereas in other they relied on informal communication or monitored a situation of a company by observing for example orders placed by customers. A similar situation was reported by $5.8 \%$ of large companies only, and it was found totally unacceptable.

\section{Testing Hypotheses}

With general results of the study in mind, the following part of the paper will apply statistical methods to validate the three hypotheses in a more detailed way. Table 5 presents results of non-parametric Kruskal-Wallis test which checked whether mean ranks of Participative Management (PAR) variable differed across companies belonging to various size groups.

Table 5. Non-Parametric Kruskal-Wallis Tests

\begin{tabular}{|c|c|c|c|}
\hline \multicolumn{4}{|c|}{$\begin{array}{l}\text { Test 1: Participative management }(P A R) \\
H_{(3.179)}=* * * 44.372 . p=0.000\end{array}$} \\
\hline Grouping & $\mathrm{n}$ & Sum of ranks & Mean rank \\
\hline micro enterprise & 30 & 1550.0 & 51.67 \\
\hline small enterprise & 34 & 2207.5 & 64.93 \\
\hline medium enterprise & 29 & 2479.0 & 85.48 \\
\hline large enterprise & 86 & 9873.5 & 114.80 \\
\hline
\end{tabular}

Source: own elaboration

The results of the analysis proved that there existed statistically significant difference (at 0.01 level) in mean values of PAR variables among the four groups of different sizes. The next step was to carry out multiple pair wise comparisons between the size groups. We applied a post hoc Dunn's test to look for stochastic dominance or median differences between the groups (table 6).

The results of the post hoc test evidenced that there were significant differences (at 0.05 level) between large and small enterprises as well as between large and micro enterprises in terms of participative management. Interestingly, even though the results did not show substantial differences between large and medium-sized enterprises, the d-statistic computed (2.6382) was just below the critical level of 2.6383 . 
Table 6. Dunn's post hoc test $(n=179)$

\begin{tabular}{|l|c|c|c|c|}
\hline \multirow{2}{*}{ Pairwise comparisons of groups } & \multirow{2}{*}{ std err } & \multirow{2}{*}{ x-crit } & \multicolumn{2}{|c|}{ PAR } \\
\cline { 4 - 5 } & & & $d$-stat & sig \\
\hline large vs. medium enterprises & 11.116 & 29.326 & 2.6382 & no \\
\hline large vs. small enterprises & 10.487 & 27.667 & $\mathbf{4 . 7 5 7}$ & yes \\
\hline large vs. micro enterprises & 10.976 & 28.958 & $\mathbf{5 . 7 5 3}$ & yes \\
\hline medium vs. small enterprises & 13.085 & 34.521 & 1.571 & no \\
\hline medium vs. micro enterprises & 13.480 & 35.565 & 2.508 & no \\
\hline small vs. micro enterprises & 12.967 & 34.209 & 1.023 & no \\
\hline \multicolumn{2}{|r|}{$\mathrm{k}=4, \mathrm{~d}$-crit $=2.6383, \alpha=0.05$} \\
\end{tabular}

Source: own elaboration

These results supported our conjecture that SMEs integrated their employees in managerial activities to the smaller degree, contrary to the large enterprises, which preferred team-oriented management. The mean rank increased along with a company size (see table 5). Therefore, the results obtained speak in favor of the hypothesis H3.

Figure 5. Significant Correlations for All Companies $(n=179)$

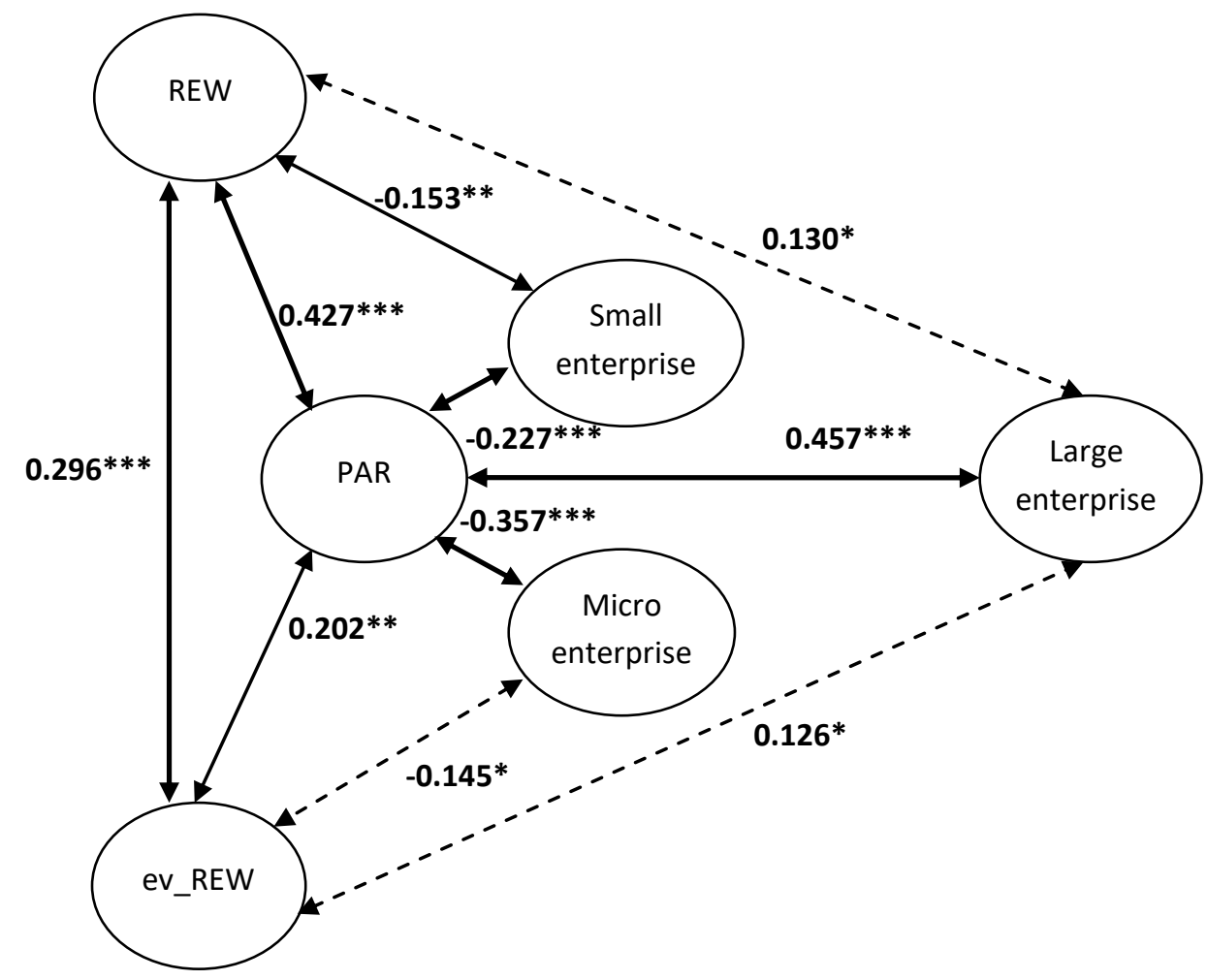

Remarks: *significant at 10\% level; **significant at 5\% level; ***significant at $1 \%$ level Source: own elaboration

The above mentioned outcomes can be also validated by correlation analyses, both for all examined companies (see figure 5) and for the SMEs alone (see figure 6). It has to be explained that figure 5 presents statistically significant correlations 
not only between an independent and two dependent variables, but also between the said three constructs and dummy variables representing size classes of enterprises.

The quantitative analysis proved the existence of the statistically valid correlation (with the coefficient of 0.427 , at a significance level of $1 \%$ ) between PAR and REW variables, what supports the hypothesis H1. Moreover, remuneration for effects was linked to a company size what was substantiated by a negative correlation (-0.153) for small enterprises and a slight positive correlation (0.130) for large ones.

A participative character of work made employees more satisfied with their remuneration (correlation coefficient of 0.202 , at a significance level of 5\%), what supported the hypothesis $\mathrm{H} 2$. Moreover, it should be noted that performance related remuneration was in general positively assessed (positive correlation of 0.296 , at a significance level of $1 \%$ between REW and ev_REW variables).

The research suggested also a possible link between a size of a company and satisfaction with remuneration. For microenterprises a negative correlation $(-0.145)$ was observed, whereas large companies tended to be evaluated better in that respect (a positive correlation coefficient of 0.126). Though in both cases a significance level of $10 \%$ had to be considered.

The research showed also a statistically valid relation between a size of a company and its willingness to implement a participative management style, what was - as said before - increasing satisfaction with remuneration. Participative management appeared to be a feature of large companies (a positive correlation of 0.457 , at a significance level of $1 \%$ ). Negative correlation were observed in case of micro and small companies (coefficients equal -0.357 and -0.227 respectively, both at significance levels of $1 \%$ ). Those facts speak indirectly in favor of the hypothesis H3.

Figure 6. Correlation Analysis for SMEs (n=93)

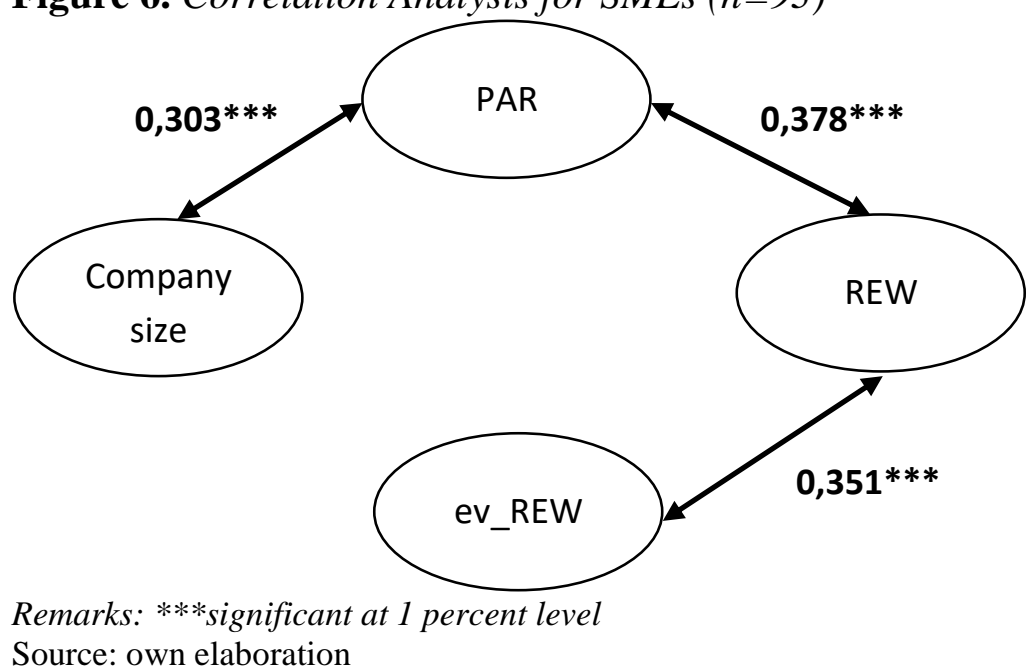

The correlation analysis for the SMEs (figure 6) confirmed that participative management style stimulated performance related remunerations (with the coefficient of 0.378 , at a $1 \%$ significance level). 
Even though, there was no statistically valid relation between participative management and satisfaction with remuneration detected, it was evidenced that performance related remuneration systems were preferred by employees (correlation coefficient of 0.351 , at a $1 \%$ significance level). Therefore, it can be claimed that among Polish SMEs a size of a company stimulated use of participative management, what implied more frequent use of performance related rewarding systems, which are in general better seen by employees. The identified implications: company size $\rightarrow$ PAR $(* * * 0.303) \rightarrow$ REW $(* * * 0.378)$ $\rightarrow$ ev_REW $(* * * 0.351)$ confirmed the hypothesis $\mathrm{H} 1$ and indirectly supported hypotheses $\mathrm{H} 2$ and $\mathrm{H} 3$.

\section{Discussion and Conclusion}

The results of the study presented in the previous part of the paper entitle to draw three main conclusions: (1) the overall appreciation for democratic leadership in Polish SMEs, (2) influences of bureaucratic culture on leadership and (3) deficient leadership skills in the SME sector.

The appreciation for democratic leadership may be observed in reference to the highest employees satisfaction scores when they were either involved in formulation of or at least fully informed on strategic and operational plans in their company. Similarly, a study on Thai companies evidenced that employees who perceive their managers as more democratic, were generally more satisfied both with levels of their participation in decision-making and their work conditions (Yukongdi 2010, p. 175). On the other hand, those most welcome situations were found only in $28.0 \%$ of the examined Polish SMEs, and much more frequent in large companies. Already a significant period of free market economy, and integration with European Union causes that leaders of former Eastern bloc become more democratic, but the changes are observed first in larger companies, more exposed to foreign organizational cultures (Ogarcă, Crăciun, Mihai 2016, p. 293).

Another observation of the authors was detecting a heritage of socialistic bureaucracy in the working environment, manifested in salaries dependent on position or time of employment, but not linked to effects or efficiency factors. As much as 43,0\% Polish SMEs used neither merit-related remuneration, nor bonuses, nor even performance related promotions systems. In that sense it is important to mentioned that a bureaucratic culture has a negative influence on leadership. Fiaz et al. (2017, p. 152) evidenced based on the example of Pakistan, that while autocratic leadership negatively affected motivation of employees, the opposite effect of democratic leaders encouraging employees' commitment may be impaired by bureaucratic organizational culture, which results from a long-term leadership deficits in a country. Furthermore, as observed in case of Romania (Mina 2012, p. 316), a combination of autocratic leadership and bureaucratic organizational cultures, characteristic for post-socialist countries, increased a distance between executive level and employees in particular if the latter did not have powerful representatives. In this respect the heritage of the 
socialism era in Poland, with its bureaucracy eliminating participation or employees in decision-making, may still be a relevant issue in interpreting results of the study.

Finally, the authors' research indicated also leadership deficiencies in many Polish SMEs. Employees from every fourth examined SMEs reported they were not instructed by managers on goals or tasks to be fulfilled. Interestingly, the employees were not concerned with this information deficit, since they did not expect anything positive from managers scrutinizing their work.

To sum up, the objective of this paper was to fill in the research gap on linking leadership to forms of and satisfaction with remuneration systems. In that sense the study contributes to a literature on participative management and rewarding strategies in several ways. Firstly, it detects and defines the relations between the abovementioned constructs on Polish data set. According to our best knowledge, there is a lack of empirical studies which analyze such relations in the context of Polish SMEs and their comparison to large enterprises with exception of the authors' research. Secondly, this study takes an employees' perspective, including that of the staff from lower strata in a company hierarchy. Adoption of this perspective is important since in countries where for years the autocratic leadership was the only option, it is observed that leaders and employees differ in evaluation of leadership style in an organization. The research from Turkey (İnandi, Uzun, Yeşil 2016) evidenced that managers describing their leadership style as democratic where often seen as authoritative by subordinates. Thirdly, our examination reflects specific business culture of Central and Eastern European countries, where democratic leadership style was not an obvious choice, where control evoked negative associations, and where employees were neither used to nor willing to take responsibility and to be evaluated or rewarded based on their performance. In this respect the study showed that the heritage of socialism era in a form of dictatorial authority has faded and given way to a more democratic, leadership-based, business culture.

Respecting the aforementioned observations a limitation of the authors' approach need to be mentioned. Firstly, the analytical model did not directly covered variables reflecting existence of autocratic or democratic leadership styles in enterprises, but investigated participative management as an indicator of democratic leadership. Secondly, the hypotheses assumed that job satisfaction was a function of job rewards as it had been indicated for example in the study of Kalleberg (1977), who argued also that work values had independent and significant effects on job satisfaction. Although in the authors' study evaluation of reward strategies was positively correlated with a type of reward strategy applied, which meant that employees were more satisfied when their remuneration had a character of pay-for-performance reward, other studies evidenced that such an assessment may not be unambiguous in all conditions. Heery (1996) and Lewis (1998), for instance, found that employees confirmed no increase in work quality as a results of applying pay-for-performance reward. Moreover, they indicated a damage to teamwork and working relationships and increased jealousies between staff members due to individual performance-related pay system which was prone to inconsistency and subjectivity in appraisals (Cox 2000). 
Such factors were not measured by variables used by the authors. Finally, there appeared a challenge of converting respondents voices into values of examined variables for particular objects. In the statistical analyses each company was treated as one research object, disregarding the fact which departments of a company respondents originated from and how many employees were consulted in providing questions on examined problems.

The authors believe though, that the limitation of the quantitative analysis may be mitigated, since the study included also narrative answers. Those answers may be further examined using text mining techniques, what is a next step on the research agenda.

\section{References}

Activity of Non-financial Enterprises in 2012. Central Statistical Office of Poland. Warsaw 2014, 54-56.

Armstrong, M. 2008. Strategic Human Resource Management. Kogan Page. London.

Arnold, K.A., Loughlin C. 2013. Integrating transformational and participative versus directive leadership theories. Examining intellectual stimulation in male and female leaders across three contexts.Leadersh. and Organ. Dev. J. 34, 1, 67-84. DOI= https://doi.org/10.1108/01437731311289974

Average Annual Wages. OECD, Stat Extracts. https://stats.oecd.org/Index.aspx?Data SetCode=AV_AN_WAGE\# (referred on 02/06/2017).

Average Employment and Remuneration in Enterprises in June 2014. Central Statistical Office of Poland. Warsaw 2014.

Baird, L., Meshoulam, I. 1988. Managing two fits of strategic human resource management. Acad. Manag. Rev. 13, 1 (Jan. 1988), 116-128. DOI= doi: 10.5465/ AMR.1988.4306802

Bass, B.M. 1985. Leadership and Performance. Free Press. New York.

Bass, B.M. 1998. Transformational Leadership: Industrial, Military, and Educational Impact. Lawrence Erlbaum Associates. Mahwah. NJ.

Bass, B.M., Riggio, R.E. 2006. Transformational Leadership ( $2^{\text {nd }}$ ed.). Mahwah. NJ: Erlbaum.

Burns, J.M. 1978. Leadership. Harper \& Row. Onursal Arkan. New York.

Cellar, D.F., Sidle, S., Goudy, K., O'Brien, D. 2001. Effects of leader style, leader sex, and subordinate personality on leader evaluations and future subordinate motivation. J. Bus. Psychol. 16, 1 (Fall 2001), 61-72. DOI= 10.1023/A:1007887721571

Cotton, J.L. 1995. Participation's effect on performance and satisfaction: a reconsideration of Wagner. Acad. Manag. Rev. 20, 2 (Apr. 1995), 276-278.

Cox, A. 2000. The importance of employee participation in determining pay system, Int. J. Manag. Rev. 2, 4 (Dec. 2000), 357-375. DOI=10.1111/1468-2370.00047

Cunningham, J., Salomone, J., Wielgus, N. 2015. Project management leadership style: a team member perspective. Int. J. Glob. Bus. 8, 2 (Dec. 2015), 27-54.

Dettert, J.R., Burris. E.R. 2007, Leadership behavior and employee voice: is the door really open? Acad. Manag. J., 50, 4 (Aug. 2007), 869-884. DOI= 10.5465/AMJ. 2007.26279183

Daniels, K., Bailey A. 1999. Strategy development processes and participation in decision-making: predictors of role stressors and job satisfaction. J. Appl. Manag. Stud. 8, 1, 27-42. 
Daniels, K., Guppy, A. 1994. Occupational stress, social support, job control and psychological well-being.Hum.Relat. 47, 12 (Dec. 1994), 1523-1544. DOI=10. 1177/001872679404701205

Dyczkowska J., Dyczkowski T. 2012. Integration of Organisational Planning with Employee Remuneration Strategies. Results of the Empirical Research on Polish Enterprises. In Proceeding. Cross-cultural Conference 2012. R. Füreder (et al.) (eds.). Shaker Verlag. Aachen.

Emmert, M.A., Taher W.A. 1992. Public sector professionals: the effects of public jobs on motivation, job satisfaction and work involvement, Am. Rev. of Public Admin. 22, 1 (Mar 1992), 37-48. DOI= 10.1177/027507409202200103

Fiaz, M., Qin S., Ikram, A., Saqib, A. 2017. Leadership styles and employees' motivation: perspective from an emerging economy. J. Dev. Areas. 51, 4 (Fall 2017), 143-156. DOI $=10.1353 /$ jda.2017.0093.

Fisher, S. 1989. Stress, control, worry prescriptions and the implications for health at work: as psychological model.InJob control and worker health. Sauter S.L., Hurrell J.J., Cooper C.L. (eds.). Wiley.Chichester.

Heery, E. 1996. Risk, representation and the new pay.Pers. Rev. 25, 6, 54-65. DOI= https://doi.org/10.1108/00483489610148536

İnandi, Y., Uzun, A., Yeşil, H. 2016. The relationship between the principals' leadership styles and their efficacy in change management. J. Educ. Sci. Res. 6, 1 (Apr. 2016), 191-209. DOI= 10.12973/jesr.2016.61.10.

International Migrations of Citizens. Central Statistical Office of Poland. Warsaw. 2013, 172.

Inyang, B.J. 2010. Strategic human resource management (SHRM): A paradigm shift for achieving sustained competitive advantage in organization, Int. Bull. Bus. Admin. 7, http://www.eurojournals.com (referred on 01/06/2014)

Kalleberg, A.L. 1977. Work values and job rewards: a theory of job satisfaction. Am. Sociol. Rev. 42, 1 (Feb. 1977), 124-143. DOI= 10.2307/2117735

Kaplan, R.S., Norton, D.P. 2000. Strategy-Focused Organization. How Balanced Scorecard Companies Thrive in the new Business Environment. MA: Harvard Business School Press. Boston.

Kim, S. 2002. Participative management and job satisfaction: lessons for management leadership. Pub. Admin. Rev. 62, 2 (Dec. 2002), 231-241. DOI= 10.1111/0033-33 52.00173

Lawler, E.E. III 1986. High Involvement Management.Jossey-Bass. San Francisco.

Ledford, G.E. Jr 1993. Employee involvement: lessons and predictions", In Organizing for the future the new logic for managing complex organizations. J., Galbraith, E.E. Lawler, III \& Associates (eds.).Jossey-Bass. San Francisco.

Lengnick-Hall, C.A.. Lengnick-Hall, M.L. 1988. Strategic human resource management: a review of the literature and proposed typology. Acad. Manag. Rev. 13, 3 (Jul. 1988), 451-470. DOI= 10.5465/AMR. 1988.4306978

Lewis, P. 1998. Managing performance-related-pay based on evidence from the financial services sector. Hum. Resour. Manag. J. 8, 2 (April 1998), 66-77. DOI= 10.1111/ j.1748-8583.1998.tb00167.x

Maloş, R. 2012. Leadership styles. Annals of EftimieMurgu University Resita, Fascicle II, Economic Studies. 421-426.

Marin, I. 2012. Increase Employee Motivation in Romanian SME's. Rev. Int. Compar. Manag. 13, 5, (Dec 2012), 804-810.

Mayo, A. 2001. The Human Value of the Enterprise: Valuing People as Assets Monitoring, Measuring, Managing. Nicolas Brealey, London. 
Milkovich, G.T., Newman, J. 2005. Compensation. McGraw-Hill Companies Inc., New York.

Mina, S. 2012. 1. The Romanian centralized organizations' resistance to change. Constanta Maritime University's Annals. 13, 18 (2012), 313-320.

Mohiuddin, Z.A. 2017. Influence of Leadership Style on employees performance: evidence from literatures. J. Marketing Manag. 8, 1 (May 2017), 18-30.

Nanjundeswaraswamy, T. S., Swamy, D R. 2015. Leadership styles and quality of work life in SMEs. Manag. Sci. Lett. 5, 1, 65-78. DOI= 10.5267/j.msl.2014.12.006.

Odiri, V.I.O. 2016. Participative leadership and organizational performance: empirical analysis of quoted oil firms on the Nigerian stock exchange. J. Acad. Res. Econ. 8, 2 (Jul. 2016), 287-293.

Ogarcă, R., Crăciun, L., Mihai, L. 2016. Leadership styles in SMEs: an exploratory study in Romania. Manag. Market. 14, 2, 283-298.

Park, S., Sturman, M.C. 2009. The relative effects of merit pay, bonuses, and long-term incentives on future job performance (CRI 2009-009). http://digitalcommons.ilr. cornell.edu/cri/7 (referred on 14/04/2014)

Pennig, S., Traut, A. 2009. Human capital management in Mittelstand. Integration von strategischen Personal controlling und Führungskräfteentwicklung. In Mittelstands controlling. Lingnau. V. (ed.). EulVerlag, 241-277.

Pitkänen, H., Lukka, K. 2011. Three dimensions of formal and informal feedback in management accounting. Manag. Account. Res. 22, 2 (June 2011), 125-137. DOI= https://doi.org/10.1016/j.mar.2010.10.004

Psychogios, A.G., Garev, S. 2012. Understanding complexity leadership behaviour in SMEs: lessons from a turbulent business environment. Emergence: Complexity \& Organization. 14, 3, 1-22.

Sauer, S.J. 2011. Taking the reins: the effects of new leader status and leadership style on team performance. J. Appl. Psychol. 96, 3 (May 2011), 574-587. DOI= 10.10 37/a0022741.

Scott, T.W., Tiessen P. 1999. Performance measurement and managerial teams. Account. Organ. and Soc. 24, 3 (April 1999), 263-285. DOI= https://doi.org/10.1016/S0 361-3682(98)00060-9

Spector, P.E. 1986. Perceived control by employees: a meta-analysis of studies concerning autonomy and participation at work. Hum. Relat. 39, 11 (Nov. 1986), 1005-1016. DOI=10.1177/001872678603901104

Structure of Wages and Salaries by Occupations in October 2012. Central Statistical Office of Poland. Warsaw 2014, 42; 65; 163.

Sturman, M.C., Short, J.C. 2000. Lump-sum bonus satisfaction: testing the construct validity of a new pay satisfaction dimension. Pers. Psychol. 53,3 (Sept. 2000), 673700. DOI=10.1111/j.1744-6570.2000.tb00218.x

Wang, Y., Poutziouris, P. 2010. Leadership styles, management systems and growth: empirical evidence from UK owner-managed SMEs. Journal of Enterprising Culture. 18, 3 (Sep 2010), 331-354. DOI= 10.1142/S0218495810000604.

Wei, L. 2006. Strategic human resource management: Determinants of fit. Res. and Pract. in Hum. Resour. Manag. 14, 2, 49-60.

Wright, P. M., McMahan, G.C. 1992. Theoretical perspective for strategic human resource management. J. Manag.18, 2 (June 1992), 295-320. DOI= 10.1177/0149206392 01800205

Yukongdi, V. 2010. A study of Thai employees' preferred leadership style. Asia Pac. Bus. Rev., 16, 1-2 (Jan. 2010), 161-181. DOI= 0.1080/13602380903168962. 
